\title{
La experiencia de niños en un programa grupal cognitivo-conductual para la ansiedad: ¿qué recuerdan 9 meses después?
}

\author{
Sara Machado, Sara Simão, Ana I. Pereira y Rita Maia \\ Universidade de Lisboa
}

RESUMEN

Este estudio explora la recordación y perspectiva de los niños 9 meses después de su participación en un programa grupal cognitivoconductual -el Programa Amigos para la Vida. Se realizaron entrevistas semiestructuradas a 26 niños (entre 9 a 13 años). Se han analizado: (1) los aspectos más recordados del programa; y (2) el nivel de comprensión de las estrategias y su uso después finalizarlo. Los resultados revelaron que los aspectos más recordados fueron sus objetivos, las actividades específicas y las estrategias aprendidas. Las dimensiones mencionadas como las más apreciadas fueron las actividades específicas y los aspectos relacionales. El aspecto considerado más importante fue la diminución de la ansiedad. Cuando se les preguntó directamente acerca de las habilidades aprendidas, ellos revelaron un mayor conocimiento y uso de estrategias relacionadas con la gestión somática de la ansiedad, el componente cognitivo y el componente de apoyo social. Se discuten las implicaciones de este estudio.

Palabras clave: terapia cognitivo-conductual; intervencion grupal; ansiedad; niños; perspectiva; recuerdo.
AbSTRACT

This study explores the recollection and perspective of children nine months after their participation in a group cognitive-behavioral program for anxious children -the Friends for Life Program. Semi-structured interviews were applied to 26 children (9-13 years). We analyzed: (1) the most recalled aspects of the program; and (2) the comprehension level of the strategies and their use after the end of the program. Results revealed that the most remembered aspects of the program were its' goals, specific activities and strategies learned. The dimensions most appreciated by the children were the specific activities and relational aspects. The aspect considered most important was the decrease in anxiety. When questioned about the skills learned, they revealed a greater knowledge and use of strategies related to the somatic management of anxiety, the cognitive component and the social support component. Children were able to do a meaningfully evaluation of their experience with the CBT intervention.

Keywords: Cognitive-behavioral intervention; group intervention; anxiety; children; perception.

Acknowledgements:This study received financial support from the Fundação para a Ciência eTecnologia (PTDC/PSI-PCL/122007/2010). The authors thank all schools, families and children, who collaborated and made this study possible. 


\section{Introduction}

Anxiety is recognized as one of the most prevalent disorders in children and adolescents, with an estimated prevalence rate of $5.7 \%$ to $17.7 \%$ (Costello \& Angold, 1995). Its impairment is also documented, as anxiety may interfere within the family, social and school contexts, causing potential medium and long-term consequences along the various dimensions of the child's life (Kendall, 1992).

Cognitive-Behavioural Therapy (CBT) is among the most efficacious treatments for anxiety disorders (e.g., Reynolds, Wilson, Austin, \& Hooper, 2012; Seligman \& Ollendick, 2011), with some studies indicating that approximately $65 \%$ of youth no longer meet diagnostic criteria for their main anxiety diagnosis at post-treatment (Kendall et al., 2005). Studies also show that the treatment gains of these CBT-based structured programs are maintained over time, even after a period of seven years post-intervention (Kendall, Safford, Flannery-Schroeder, \& Webb, 2004). The therapeutic programs for the treatment of child's anxiety are addressed at a range of anxiety disorders and aim to modify maladaptive thinking and change avoidant behavioural patterns, assumed to be risk factors for the development of different anxiety disorders (Kendall \& Suveg, 2006). Generally, the intervention is focused first on the recognition of anxious symptoms and learning different strategies to manage anxiety effectively (e.g., cognitive restructuring, relaxation techniques, problem solving). After children learn about anxiety and coping strategies, they are encouraged to use these coping strategies while practicing graduated exposure to feared situations.

Although there is large and compelling evidence of the efficacy of CBT in reducing anxiety in youth, there still is a significant percentage of children that do not respond adequately to CBT. Therefore, the efficacy of CBT can be improved by studying therapy processes that may predict outcomes. Questions like how and in what conditions CBT works are still largely unanswered (Hogendoorn et al., 2014). Understanding the client's perspective about therapeutic processes is a possible line of research to explore these questions. Also, in psychological interventions with children, the children's point of view is rarely considered during service assessments (Davies \& Wright, 2008). This is specially concerning taking into consideration that referrals to psychological treatment are typically initiated by significant adults in the child's network (parents, teachers, etc.) and therefore the external motivation to engage in therapy can pose significant challenges to treatment adherence and results (Persson, Hagquist, \& Michelson, 2017). These aspects are particularly important to CBT, where an active client participation is critical for skill learning and training and involvement in exposure exercises (Macleod et al., 2014).

To our knowledge very few studies have attempted to explore the children's perspective on the therapy process. In one of these studies by Kendall and SouthamGerow (1996), 36 youth, between the ages of 11 and 18 years old, were interviewed on what they recalled and considered important from 
their psychological treatment, a cognitivebehavioral intervention for anxious children. Overall the children perceived the therapeutic relationship and dealing with problems as the most important aspects of the intervention. The latter was also the most recalled aspect of psychological treatment, followed by learning the coping strategies, the exposure tasks and the games and activities. These results suggest that children recall and appeal to particular strategies and components of the therapeutic intervention.

Having information about how children experience the therapeutic process, if that experience helped them to accomplish their objectives, what were the aspects of the intervention more valued and useful for them, what skills and strategies they have learned with that experience and whether they use those skills and strategies in their daily lives after therapy is terminated is important for ethical as well as pragmatic reasons, allowing to design more sensitive and effective interventions (Strickland-Clark, Campbell, \& Dallos, 2000). Moreover, qualitative and exploratory studies about children's therapeutic experiences could provide valuable data about key elements of the therapeutic process, including factors promoting child's motivation and adherence (Biering \& Jensen, 2011), as well as knowledge about mediating variables that contribute to the effectiveness of treatment (Maric, Heyne, MacKinnon, van Widenfelt, \& Westenberg, 2013). The present study will explore children's perspectives about their experience of participation in a group cognitive-behavioral program for anxious children, conducted in schools, nine months after their participation. Specifically the aims of the study were to determine which of the aspects and components of the intervention were the most recalled; and (2) the comprehension level of the strategies learned and their use after the end of the program.

\section{Method}

\section{Participants}

The sample consisted of 26 children, aged 9 to 13 years $(M=11.12, S D=1.24)$ who had participated in a cognitive behavioral group intervention for anxious children (the FRIENDS for Life Program, Barrett, 2010), 9 months before. Of the total sample, 53.8\% were boys. The participants had been diagnosed with one of four anxiety disorders (social phobia, $\mathrm{n}=$ 8; generalized anxiety, $\mathrm{n}=8$; specific phobia, $\mathrm{n}=6$; and separation anxiety, $\mathrm{n}=4$ ) at preintervention.

\section{Measures}

\section{Children's Anxiety}

The Screen for Child Anxiety Related Emotional Disorders - Revised version (SCARED-R; Muris, Merckelbach, Schmidt, \& Mayer, 1999) is a self-report questionnaire containing 69 items that assess symptoms of various anxiety disorders in children, in which children and their parents rated how frequently the child experiences each symptom on a 3-point scale (0 - never or almost never, 1 sometimes, or 2 - often). The item scores can be combined into separate scores for each anxiety disorder and into a total anxiety score. The Portuguese version of the SCARED-R showed 
high levels of internal consistency, good testretest reliability, and adequate convergent and discriminant validity (Pereira et al., 2015).

The Anxiety Disorders Interview Schedule for Children, Child and Parent Versions (ADIS-C/P; Silverman \& Albano, 1996) is a semi-structured interview for diagnosing anxiety disorders in youths (7-18 years) that probes respondents for the main criteria of a diagnosis, which when positively endorsed are then followed by a more detailed assessment of symptoms, level of fear, avoidance, and interference. Previous studies show that ADISC/P has acceptable to excellent inter-rater agreement (Lyneham, Abbott, \& Rapee, 2007). In the current study, parents and children were interviewed together following the procedure described by Khanna and Kendall (2010). In this sample, results showed that the inter-rater reliability for different anxiety disorders was high, with all kappa values being .89 or higher.

Interview regarding the program: Recalling

\section{Friends Program}

The interview was developed specifically for this study and was based on the interview developed by Kendall and Southam-Gerow (1996). The questions are subdivided in two groups, in a total of 14 questions - 6 questions related to the aspects that the children most recalled and appreciated from their participation in the FRIENDS program (General Recall, Recall of the program's goals, Recall of individual goals, Accomplishment of the established individual goals, Features and components most enjoyable, Features and components most important) and 8 related to the degree of knowledge and use of the coping strategies that the children demonstrated and considered having at the time of the interview (Knowledge of the meaning of the acronym F-R-I-E-N-D-S, Knowledge and use of the strategies learned during the program (e.g., in the FRIENDS program you've learned to be aware of your signs of anxiety and of the clues that your body gives you about what you are feeling. Do you remember your signs or clues? Are you still aware of those signs nowadays?). In order to consider the children had some knowledge of the strategy they had to explain it, providing a definition or a representative example of said strategy. In terms of the use of the strategy, we called for a yes or no answer, and requested the children to quantify the use of the strategy on a 0-8 scale - answers from 0 to 2 were coded as no, answers from 3 to 5 were coded as sometimes and answers from 6 to 8 were coded as yes.

\section{Procedure}

The data was collected within the context of a larger study on the mediators and moderators of treatment for childhood anxiety. The study was approved and organized in collaboration with the school boards and teachers of the schools involved. All children from the $3^{\text {rd }}$ to $6^{\text {th }}$ grade of 11 schools were invited to participate in the study, with the only exclusion criterion being the inability to understand the questionnaires. After obtaining initial parental informed consent, a two stage screening procedure took place. The first stage phase consisted of a universal screening process to identify children with 
high levels of anxiety symptoms, in which children who were authorized to participate in the study (74\%) answered the child's version of SCARED-R in the school setting, while their mothers filled out the questionnaire at home ( $n=1,065$ ). During the second phase, those who scored above the $95^{\text {th }}$ percentile on the total scale and/or the subscales that measured generalized anxiety disorder, separation anxiety disorder, or social phobia on either the child or the parent version of the SCARED-R were invited for a clinical evaluation of their anxiety symptoms by means of ADIS-C/P ( $\mathrm{n}$ $=275)$. The majority of participants $(80 \%)$ continued their participation and agreed to undergo a joint mother-child interview, which was administered by a trained research assistant. The children who met criteria for an anxiety disorder as the main diagnosis were invited to participate in a group cognitive behavioral intervention (FRIENDS for Life Program). Finally, 30 children who had participated in the group program, were randomly selected from the intervention group sample and invited to participate in the present study, nine months after the program was completed. From these children, 28 were eligible and 26 accepted to participate (93\% of those eligible). The interviews were conducted by three researchers whom the children had never met with the objective of reducing the social desirability effects in children's reports.

\section{Group CBT - FRIENDS for Life Program}

The FRIENDS for Life Program (Barrett, 2010; Pereira, Marques, Russo, Barros, \& Barrett, 2014) is a CBT group intervention for anxious chil- dren that consists of eleven weekly sessions, two sessions for the parents only, and one extra booster session for the children. The program addresses the cognitive, physiological and behavioral aspects of anxiety, teaching skills and strategies to help children cope with anxiety, including relaxation training, cognitive restructuring, exposure, problem-solving, contingency management and social support (family and peers). All of the sessions have the same structure - they begin with a warm-up activity (Your Happy Thing for The Week), and continue on to the recall of the previous session and the introduction to a new coping strategy represented by the F-R-I-E-N-D-S acronym ( $\mathrm{F}$ - Feelings: Identifying feelings by recognizing body clues; $\mathrm{R}$ - Relax: Practicing a variety of relaxation techniques; I - I can try: Awareness of unhelpful thoughts and replacement of those with helpful ones; E - Explore Solutions and Coping Step Plans: Breaking down a challenging situation into small steps that gradually increase in difficulty; N - Now reward yourself; D - Do it every day: Incorporating the coping strategies into everyday life; S - Smile! Stay calm and talk to your support networks), which is carried out by means of different enjoyable activities (Barrett, 2010). At the end of each session the children summarize what they've learned and participate in a relaxation activity. For each session, there are homework activities to be completed between sessions in order to strengthen and generalize the learned strategies. The program was conducted in the school setting by four trained clinical psychologists, with a minimum experience of 1 year in the program delivery. Each group consisted of 3-7 children 
and was run by one facilitator. All sessions were reviewed in weekly supervision meetings by a senior clinical psychologist.

\section{Data analysis}

The interviews were conducted, during approximately 20 minutes each, by three different interviewers using a previously prepared script and audio equipment to record the answers with consent from the participants. The answers were transcripted and then coded by three independent raters using QRS Nvivo 10. The content analysis of the interviews was based on a process of inductive analysis, which resulted in the construction of a category tree. Inter-rater agreement scores ranged between substantial and almost perfect agreement $(\mathrm{K}=$ .72 and $\mathrm{k}=1)$.

\section{Results}

Recall and perception of the cognitive behavioral intervention

The majority of the children $(n=24)$ were able to recall at least one aspect of the intervention. $31 \%(n=14)$ of those responses referred to the recall of procedures and adherence to the intervention, $24 \%(n=10)$ to the aims of the program (e.g., managing feelings and dealing with problems), 19\% ( $n=8$ ) to specific activities (e.g., Milkshake Breathing; Thought Ballons), 19\% ( $n=8)$ to coping strategies and $7 \%(n=3)$ referred to the results of the intervention.

Regarding the recall of the objectives of the Friends for Life Program, 77\% $(n=20)$ of the participants were able to identify a goal of the program that was consistent with the actual aims of the intervention (e.g., "Remaining calm and not being so nervous (...) beating our fear, which was only inside our heads, and wasn't real"). In terms of the individual goals defined by each child in the beginning of the program, $41 \%(n=11)$ of the responses referred to diminishing specific phobia, $26 \%(n=7)$ to diminishing social phobia or shyness, $18 \%$ ( $n=$ 5) to diminishing other anxiety problems (e.g., separation anxiety) and the remaining 15\% (n $=4$ ) referred to other aspects (e.g., making new friends, promoting well-being). When asked if they accomplished the goals of the program, $65 \%(n=17)$ of the participants responded positively, while $27 \%(n=7)$ said they did so, but only partially.

Overall children considered that the most important aspect of the program was diminishing their anxiety $(81 \% ; n=22)$. In terms of what was considered most enjoyable, 39\% ( $\mathrm{n}$ $=16$ ) of the responses referred to the specific activities of the program (e.g., Party and Video; Milkshake Breathing; Thought Ballons), 34\% (n $=14)$ to the relationship established with the facilitator and the group colleagues, and 17\% $(n=7)$ to the procedures, while the remainder $6 \%(n=4)$ referred to the strategies learned and the results of the intervention.

Knowledge and use of the coping strategies learned during the intervention

Each main strategy learned in the program was introduced and represented by a letter of the F-R-I-E-N-D-S acronym. This part for the interview was designed to analyze the knowledge and use of the strategies learned during the program. Regarding the recall and 
knowledge about the meaning of the acronym F-R-I-E-N-D-S, only one participant was able to answer the question. However, when asked specifically about the learned skills most of the children recalled some aspects of each of the strategies. Table 1 presents the percentage of the participations by level of knowledge and use of the strategies learned during the intervention. Overall, children presented at least some knowledge concerning the identification of feelings, including anxiety and its body clues as well as its management through relaxation and deep breathing, the identification of anxious thinking and of alternative coping thoughts, self-reinforcement, identification of support networks and seeking social support. In terms of use of the strategies, children seem to present the same pattern. The behavioral component of the intervention (exposure and problem-solving) seems to be the least known and used one.

\section{Discussion}

While the efficacy of CBT in the treatment of anxiety disorders has been largely studied and supported, there are few studies that focus on the child's perception of these interventions. Further knowledge of the children experience and what they perceive as useful during the intervention could provide important information to improve acceptance and adherence (Biering \& Jensen, 2011) and, consequently, to improve efficacy and to maximize the impact of CBT programs.

The results of this study show that in general children were able to recall meaningful aspects of the intervention. The most recalled aspects were the aims of the program (e.g., "Some activities and suggestions for when we are anxious or nervous, for us to calm down"), as well the procedures of the intervention (e.g., "When we succeeded on an exposure assignment, we would get a sticker"). The

\section{Tabla 1}

Level of participant's knowledge and use of the strategies learned during CBT intervention at 9 months post-intervention

\begin{tabular}{|c|c|c|c|c|}
\hline \multirow[t]{2}{*}{ Strategy } & \multicolumn{2}{|c|}{ Knowledge (\%) } & \multicolumn{2}{|c|}{ Use (\%) } \\
\hline & $\begin{array}{l}\text { At least some } \\
\text { knowledge }\end{array}$ & No knowledge & $\begin{array}{l}\text { At least some } \\
\text { times }\end{array}$ & Never \\
\hline Recognizing anxiety & 88 & 12 & 88 & 12 \\
\hline Relaxation and breathing training & 92 & 8 & 88 & 12 \\
\hline Cognitive restructuring & 92 & 8 & 88 & 12 \\
\hline Exposure & 58 & 42 & 42 & 58 \\
\hline Problem solving & 23 & 77 & 27 & $65^{*}$ \\
\hline Self-Reinforcement & 88 & 12 & 85 & 15 \\
\hline Social Support & 96 & 4 & 96 & 4 \\
\hline
\end{tabular}

*Note: $8 \%$ of the children weren't able to answer the question about the use of the problem-solving skill they had learned during the intervention. 
vast majority correctly identified the aims of the intervention, and their own goals for the intervention (e.g., "Overcoming the fear of the dark."). The program was seen as useful, especially in diminishing their anxiety and learning different strategies to deal with difficult situations. The participants identified diminishing their anxiety as the most important aspect in the FRIENDS program. These findings are similar to the child-therapy study of recall by Kendall and Southam-Gerow (1996), in which children perceived dealing with problems as one of the most important aspects of the intervention. Therefore, the results of this study support the idea that children who complete the intervention are satisfied with the results accomplished.

Overall, the most appreciated aspects were specific activities of the program (e.g., "The pizza massage") and the interactions with the facilitator and other group participants. These results reinforce the importance of the patienttherapist relationship but also the relationship with the other children, and give some support to the idea that relational aspects are valued aspects of psychological treatments. Previous research shows that a good alliance with the therapist is related to children's involvement in the therapeutic process (McLeod et al., 2014) and predicts therapy outcomes, although with small effect sizes (see for example, the metaanalysis of McLeod, 2011).

Regarding the knowledge about the learned strategies, the participants seem to present some knowledge in terms of the somatic component of the intervention (identifying anxiety and managing its somatic component) as well as the cognitive component of the program (identifying negative thoughts and cognitive restructuring). Nevertheless, children present less knowledge and use of the exposure and problem-solving components of the program. These results can be explained in terms of the time that is devoted to the learning and training of each strategy. The training of the strategies that focus on the somatic and cognitive management of anxiety is done in several sessions, but only one sessions is dedicated to problem-solving. To learn a strategy children must have enough time to practice, receive feedback and generalize the strategy to different contexts of their lives, which doesn't happen in the same extent with the problem-solving component. Consistent with this hypothesis, a metaanalysis conducted by Reynolds, Wilson, Austin and Hooper (2012) that examined the effects of psychological therapies for youth with anxiety disorders found that moderate to large treatment effects are associated with nine or more sessions. One other explanation for the lesser use of the behavioral component has to do with motivational factors. The elaboration and accomplishment of an exposure plan requires more effort and motivation, and can be difficult for the children to do by themself (Kendall et al., 2005).

Overall, considering the differences between the knowledge and use of the exposure and problem-solving components of the intervention and the rest of the components (somatic and cognitive components) and taking into account that only one child recalled the meaning of the acronym F-R-I-E-N-D-S 
(that indicated the sequence of coping steps to manage anxiety), we can conclude that children tend to learn and use the different components of CBT intervention as a toolkit rather than using them in a predetermined sequence, when they are faced with a difficult situation. Therefore, they select and use one or a combination of some of the strategies as opposed to using all of them sequentially, when needed. These results emphasize the importance of applying CBT procedures in an individualized and flexible manner, in particular when the treatment follows a manual (Chu \& Kendal, 2009).

The results of this study also reinforce the importance of studying the child's perception on CBT intervention as well as the importance of studying which of the CBT intervention components are most crucial for anxiety reduction. These findings could have an important impact on the design and implementation specificities of such programs in the future, allowing to better captivate the participants and thus promote an increased efficacy of the intervention.

This study suffers from a number of limitations, including the fact that the data was limited to the child's report, the small sample dimension, and the focus only on children that completed the program (excluding drop-outs). However, given the scarcity of research in this area, the qualitative methodology used in the present study offers a valuable approach. Future studies, with larger samples, are needed to explore children's perspectives about their experiences with the therapeutic process. Namely, it would be interesting to examine how the child's perceptions are related to the involvement in the therapeutic process and to the outcomes of the therapy.

\section{References}

Barrett, P. M. (2010). FRIENDS for Life for children. Participant workbook and leader's manual. Brisbane, Australia: Barrett Research Resources.

Biering, P., \& Jensen, V. (2011). The Concept of Patient Satisfaction in AdolescentPsychiatric Care: A Qualitative Study. Journal of Child and Adolescent Psychiatric Nursing, 24, 3-10. doi:10.1111/j.1744-6171.2010.00261.x

Chu, B. B., Kendall, P. C. (2009). Therapist responsiveness to child engagement: flexibility within manual-based CBT for anxious youth. Journal of Clinical Psychology, 65, 736-754. doi: 10.1002/jclp.20582

Costello, E., \& Angold, A. (1995). Epidemiology. In J. March (Ed.). Anxiety disorders in children and adolescents (pp. 109-124). New York, NY: Guilford Press.

Davies, J., \& Wright, J. (2008). Children's Voices: A Review of the Literature Pertinent to Looked-After Children's Views of Mental Health Services. Child and Adolescent Mental Health, 13, 26-31. doi:10.1111/j.14753588.2007.00458.x

Hogendoorn, S. M., Prins, P. J. M., Boer, F., Vervoort, L., Wolters, L. H., Moorlag, H.,... de Haan, E. (2014). Mediators of Cognitive Behavioral Therapy for Anxiety-Disordered Children and Adolescents: Cognition, Perceived Control, and Coping. Journal of Clinical Child \& Adolescent Psychology, 43, 486-500. doi:10.1080/15374416.2013.8077 36

Kendall,P.C.(1992).Childhood coping:Avoiding a lifetime of anxiety. Behaviour Change, 9, 1-8. doi:10.1017/S081348390000615X

Kendall, P. C., Robin, J. A., Hedtke, K., Suveg, C., Flannery-Shroeder, E., \& Gosch, E. (2005). Considering CBT with anxious youth? Think exposures. Cognitive and Behavioral Practice, 12, 136-150. doi:10.1016/S10777229(05)80048-3 
Kendall, P., Safford, S., Flannery-Schroeder, E., \& Webb, A. (2004). Child anxiety treatment: Outcomes in adolescence and impact on substance use and depression at 7.4-year follow-up. Journal of Consulting and Clinical Psychology, 72, 276-287. doi:10.1037/0022006X.72.2.276

Kendall, P. C., \& Southam-Gerow, M. A. (1996). Long-term follow-up of a cognitivebehavioral therapy for anxiety-disordered youth. Journal of Consulting and Clinical Psychology, 64, 724-730. doi:10.1037/0022006X.64.4.724

Kendall, P. C., \& Suveg, C. (2006). Treating anxiety disorders in youth. In P.C. Kendall (Ed.). Child and adolescent therapy: Cognitivebehavioral procedures (3rd ed.) (pp. 243294). New York, NY: Guilford Press.

Khanna, M. S., \& Kendall, P. C. (2010). Computerassisted cognitive behavioral therapy for child anxiety: Results of a randomized clinical trial. Journal of Consulting and Clinical Psychology, 78, 737-745.doi:10.1037/ a0019739

Lyneham, H. J., Abbott, M. J., \& Rapee, R. M. (2007). Inter-rater reliability of the anxiety disorders interview schedule for DSMIV: Child and parent version. Journal of American Academy of Child and Adolescent Psychiatry, 46, 731-736. doi:10.1097/ chi.0b013e3180465a09

Maric, M., Heyne, D. A., MacKinnon, D. P., van Widenfelt, B. M., \& Westenberg, P. M. (2013). Cognitive mediation of cognitivebehavioural therapy outcomes for anxietybased school refusal. Behavioural and Cognitive Psychotherapy, 41, 549-564. doi:10.1017/S1352465812000756

McLeod, B. D. (2011). Relation of the alliance with outcomes in youth therapy: A metaanalysis. Clinical Psychology Review, 31, 603616.

McLeod, B. D.; Islam, N. Y, Chiu, A. W., Smith, M. M., Chu, B. C., Wood, J. J. (2014). The relationship between alliance and client involvement in cbt for child anxiety disorders. Journal of Clinical Child \& Adolescent Psychology, 43, 735-741, doi: 10.1080/15374416.2013.850699
Muris, P., Merckelbach, H., Schmidt, H., \& Mayer, B. (1999). The revised version of the Screen for Child Anxiety Related Emotional Disorders (SCARED-R): Factor structure in normal children. Personality and Individual Differences, 26, 99-112. doi:10.1016/S01918869(98)00130-5

Pereira, A. I., Muris. P,. Barros, L., Goes, R., Marques, T., Russo, V. (2015). Agreement and discrepancy between mother and child in the evaluation of children's anxiety symptoms and anxiety life interference. European Child \& Adolescent Psychiatry, 24, 327-37, doi: 10.1007/s00787-014-0583-2

Pereira, A. I., Marques T., Russo, V., Barros, L., \& Barrett, P.M. (2014). Effectiveness of the FRIENDS for life program in Portuguese schools: Study with a sample of highly anxious children. Psychology in the Schools, 51, 647-657. doi:10.1002/pits21767

Persson, S., Hagquist, C., \& Michelson, D. (2017). Young voices in mental health care: Exploring children's and adolescents'service experiences and preferences. Clinical Child Psychology and Psychiatry, 22, $140-151$.

Reynolds, S., Wilson, C., Austin, J. \& Hooper, L. (2012) Effects of psychotherapy for anxiety in children and adolescents: A meta-analytic review. Clinical Psychology Review, 32, 251262. doi: 10.1016/j.cpr.2012.01.005

Seligman, L., \& Ollendick, T., (2011). Cognitive behavioral therapy for anxiety disorders. Child and Adolescent Psychiatric Clinics of North America, 20, 217-238. doi:10.1016/j. chc.2011.01.003

Silverman, W., \& Albano, A. (1996). The Anxiety Disorders Interview Schedule for ChildrenIV (Child and parent versions). San Antonio, TX: Psychological Corporation.

Strickland-Clark, L., Campbell, D., \& Dallos, R. (2000). Children's and adolescent's views on family therapy. Journal of Family Therapy, 22, 324-341. doi:10.1111/1467-6427.00155 